\title{
THE BIRTH OF MARGARET SANDOM
}

\author{
Colonel B. A. GAVOURIN, M.B., B.S., F.R.C.S., M.R.C.O.G.
}

Military Maternity Hospital, Woolwich

MANY hundreds of birth registrations concerning wives of servicemen stationed in Woolwich since 1838 , about the time registration became mandatory, are to be found in the archives of its Town Hall.

There is evidence that up to 1861 a very few of these babies were born in at least one of the existing military hospitals in Woolwich but that the majority were delivered in soldier's huts, private houses or in quarters in the barrack areas surrounding these hospitals. It is suggested that the one birth listed as occurring in the Royal Artillery Hospital in December 1856 and notified by the husband who is recorded as living in the Royal Artillery Hospital and possibly working there, actually took place in what must have been a hospital married quarter. Certainly for three years from 1861 entries were made against the 'General Hospital' and the admission of service personnel to this establishment was the only indication that it was in effect a military one.

On the 6th March 1863, however, at the Garrison Female Hospital in Woolwich, the wife of Gunner William Sandom gave birth to a daughter. Information concerning this was given to the Registrar of Births at the local Town Hall on the 13th April 1863 not by Gunner Sandom, but a certain Elizabeth Hay who described herself as an "occupier" of the Female Hospital. This would account for the incorrect spelling of the surname "Sandon" by the Registrar, for not only could Mistress Hay not write and found it necessary ' to make her mark' in the register but it must be assumed that she also could not spell. Mr. William Jackson wrote down exactly what he heard and it is likely that Elizabeth Hay's diction was in addition to her illiteracy not perfect.

As to the identity of Mistress Hay, all that can be said is that she was not so much an "occupier" as an occupant, that is an inmate of the hospital. One cannot be sure whether she was indeed a midwife, a resident maid or even a sickroom neighbour. Neither can one be sure whether the favoured Mrs. Sandom, was just a busybody or was somehow recompensed for her journey down the hill into Woolwich town.

Lastly, evidence appears to point to the fact that Ann Sandom was still confined to hospital some 38 days following her parturition, perhaps suffering from a form of 'puerperal exhaustion'.

As to why Sandom failed to inform on his wife personally was due to the fact that at the relevant time the Gunner was otherwise engaged in his military duties and thus prevented from doing so.

A reference to the Muster Rolls of the Public Records indicated that William Sandom had enlisted in the Royal Artillery on 22 March 1853 at the age of 19 years as a Gunner and Driver. He was obviously still serving with the colours at the time of his daughter's birth in 1863 but not in England. It has been ascertained however that he was playing a purely peaceful role with his battery in either Malta or Corfu. These are the two stations, to which Laws states in his records that the batteries of 3 Brigade were assigned. 


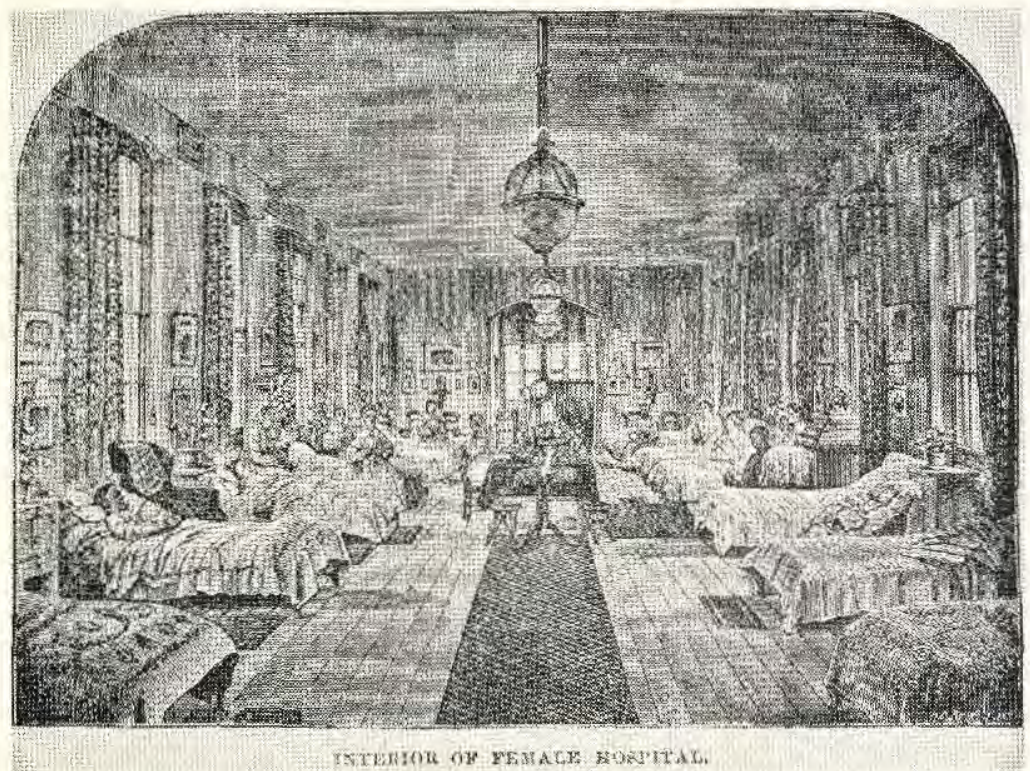

Fig. 1

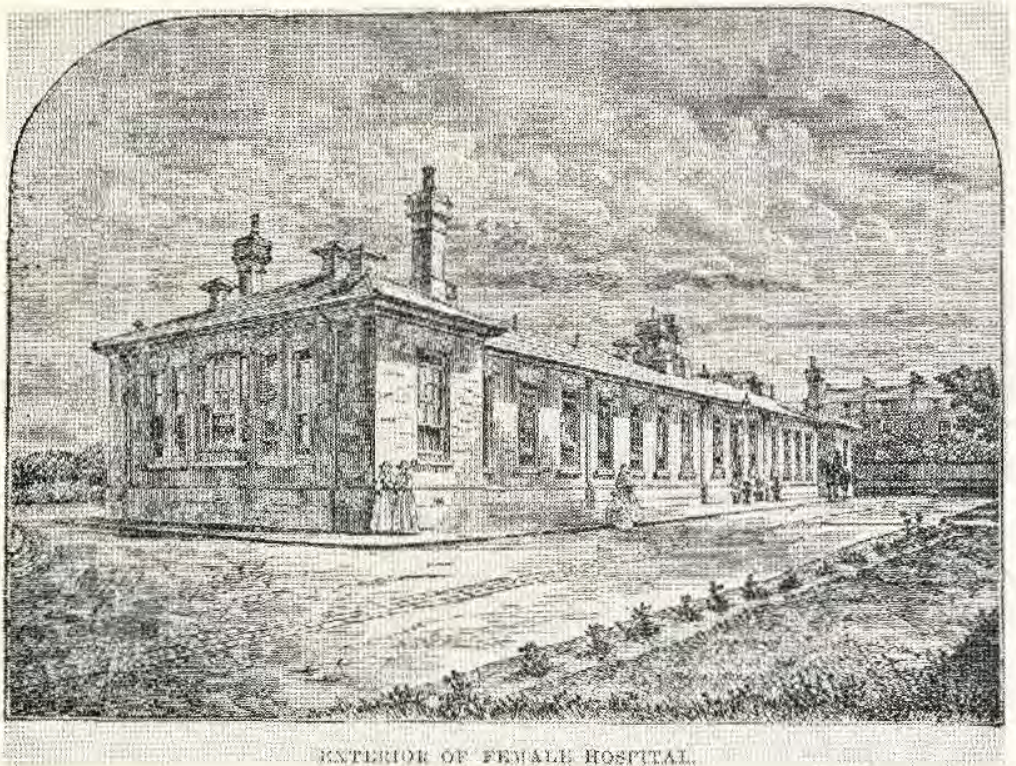

Fig. 2

For the record, Gunner Sandom served in the Crimea, was awarded a medal with an Inkerman clasp, was discharged from the Army in 1874, at the age of 40 years. Some time later he became a Chelsea Pensioner. 
The Garrison Female Hospital has been described as being located between Mill Lane, the Woolwich New Road of today, and Gunner Lane, and sited on or near Barrack Court and adjacent to Rose Bank. It was also in close proximity to Gunner Sandom's house, No. 6, Sandy Hill. Quoting from Vincent's "Warlike Woolwich" it was

" a modest building retiring behind what is known as the Auxiliary Hospital, near the White Gate. It is a little model of its kind, and does a most useful work; and we call attention to it, not so much for the purpose of attracting visitors, though they (ladies especially) will always be welcome, as to advocate the claim it has upon those who have means and the disposition to help works of charity, for it is mainly supported by voluntary subscriptions."

A careful comparison of the West facade of the present day Military Maternity Hospital with an old print of the Garrison Female Hospital of one hundred and nine years ago, mentally slicing away the more recently added annexes and nursery, locating and counting the chimney stacks, the windows and the very drain-pipes, will show that the main axis of the Military Maternity Hospital and that yesterday hospital "for soldiers" wives and children " as depicted on the print is one and the same (Figs 1 and 2).

A random Garrison census in 1881 revealed that the number of female "inmates" was 18 and that there were 3 male patients, presumably children. Births continued at the Garrison Female Hospital until 1916 when it was apparently closed to female patients presumably to cater for war wounded.

The register showed that in December 1919 the hospital once again provided a maternity service, but at this time it was called the Military Hospital, New Road. At this point it should be stressed that Mill Lane which was connected by New Road to the Plumstead Road, became the continuation of New Road and was given that title. In June 1939 the name of the road was changed to Woolwich New Road to distinguish it from other New Roads in the surrounding areas.

The hospital was closed in September. 1939 at the beginning of hostilities and was not re-opened until August 1946 when it was re-named the Military Families Hospital. On the 1 st January 1962 it was again re-named, this time the Military Maternity Hospital, which name it still bears.

\section{Acknowledgements}

Acknowledgement is made for the assistance received from. Mr. H. Blackman, M.I.R. Late Registrar of Births, Town Hall, Woolwich, Mr. G. H. Roger, M.I.R. Registrar of Births, Town Hall, Woolwich, Major R. G. Bartelot, R.A. (Retd.), Librarian, Royal Academy, Woolwich and Mrs. P. K. Jones, Clerical Assistant, Library, Royal Academy, Woolwich. Illustrations are by courtesy of PACE, Charlton.

I also thank the Editor, Gunner Magazine for permission to re-publish this article which appeared in Issue No. 28, March 1973.

\section{BIBLIOGRAPHY}

VINCENT, W. T. "The Record of the Woolwich District."

VINCENT, W. T. " Warlike Woolwich".

LAws, M, E. S. " Battery Records of the Royal Artillery. Vol, 11, 1859-1877.

Public Records OfFICE. "Muster Rolls." 